\title{
Evaluation of the experiences of family members whose deceased relative donated tissues at the NHSBT dedicated donation facility in Speke, Liverpool.
}

The final publication is available at www.springerlink.com.

\section{Corresponding author}

Dr Tracy Long-Sutehall

Senior Research Fellow/NIHR Post Doc

Faculty of Health Sciences

University of Southampton

Southampton, SO17 1BJ.

Direct Tel. No. 02380598224

E-mail T.Long@soton.ac.uk

Emma Winstanley

Manager, National Referral Centre

NHS Blood and Transplant - Tissue Services

Anthony J. Clarkson

Assistant Director - Organ Donation

NHS Blood and Transplant

Professor Magi Sque

School of Health and Wellbeing,

Centre for Health and Social Care Improvement,

University of Wolverhampton and The Royal Wolverhampton NHS Trust

Hospitals Trust. 


\section{Introduction}

Donation of human tissue for transplant and research has historically been facilitated within the hospital mortuary. In a bid to control the conditions under which tissue for transplantation is retrieved and in response to European guidance on quality ${ }^{1}$, NHSBT Tissue Services opened a facility dedicated to the retrieval of tissues under strictly controlled conditions in Speke, Liverpool. The Dedicated Donation Facility [DDF] in Speke, Liverpool opened in 2006 and was the first of its kind in the UK.

\section{Background}

In considering opening this facility it was recognised that there needed to be a clear distinction between the consented retrieval of tissues for transplantation and research, and the un-consented retrieval and retention of tissue and organs that had occurred in the past ${ }^{a}$. In view of the dedicated facility being sited in Liverpool, a City closely associated with the Alder Hey retention scandal, NHSBT Tissue Services consulted widely about the proposed DDF; and in conjunction with the Royal College of Pathologists commissioned an independent market research company to explore the attitudes of donor families to their deceased relative being transferred to the new facility for tissue donation. As this consultation gained positive responses regarding moving potential donors to the dedicated facility, it was agreed that a two year pilot study of donor transfer would be undertaken.

The pilot study was guided by a Steering Group which included representatives from the: Royal Collage of Pathology, the Coroners' Society, British Medical Association Ethics Committee and donor families. The pilot study included identifying hospital sites within a 40 mile radius of the DDF that could facilitate potential tissue donors.

\footnotetext{
${ }^{\text {a }}$ For a detailed report see Sque et al [2008] ${ }^{2}$
} 


\section{The Alliance Site Model [ASM]}

In order to facilitate donation at the DDF, three hospitals from Liverpool were signed up as Alliance Sites. This necessitated discussions with Trust Boards and the development of close working relationships as the model of referral for the Alliance Sites removes the responsibility for discussing and requesting tissue and corneal donation with a bereaved family from the health professionals who are providing and facilitating end of life care within the Alliance Site Hospitals. Health professionals within the Alliance Sites are instead tasked with: providing family members with a leaflet discussing tissue donation, telling the family that they may receive a call from TS and notifying the National Referral Centre [NRC] of all deaths occurring within their ward areas and supplying contact details of the next of kin to the NRC. The request to the family for corneal and multi tissue donation is therefore made by specially trained registered nurses based in the NRC.

Operationally, the facility has been deemed a success and therefore NHSBT Tissue Services now intend to expand the DDF model to a larger geographical area. Before doing so, and as part of the two year pilot study, the experiences and views of family members who had agreed and experienced the transfer of their deceased relative to the DDF for tissue retrieval were explored and assessed. To this end an independent evaluation team at the University of Southampton was requested to carry out an audit of the experiences of family members whose deceased relative had donated tissues at the NHSBT DDF in Speke, Liverpool. This report documents the process and outcome of that evaluation. 


\section{Aims of the evaluation}

Aim 1: To understand the decision-making process of those family members who agreed to their deceased relative being moved to the DDF at Speke so that tissue retrieval could take place.

Aim 2: To identify any concerns that family members had about their relative being moved and their views on how these concerns were addressed.

Aim 3: To gain insight into the perceptions of family members regarding the 'service' provided to them by NHSBT Tissue Services.

\section{Design and methods}

A service evaluation applying qualitative data collection methods and framework analysis ${ }^{3}$ were the methods chosen. The framework approach has been developed specifically for applied or policy relevant qualitative research in which the objectives of the investigation are typically set in advance and shaped by the information requirements of the funding body/service organisation ${ }^{4}$, in this case NHSBT Tissue Services.

\section{Data collection}

Data collection was facilitated by face-to-face interviews with family members. The original proposal indicated that face to face interviews and focus groups would be carried out, but as no family member selected participating in a focus group, interviews were carried out at a place and time acceptable to the participant and lead evaluator.

\section{Data analysis}

Following each interview, the digital-recording was listened to several times, until familiarity with the data was established. Recorded interviews were transcribed. Familiarity facilitated recognition of important ideas and patterns such as sequencing or repetition of experiences, views and opinions. Similarities and differences in the 
data and developing themes were noted in memos and formed a preliminary analysis of the data. Analysis drew on modified framework analysis techniques ${ }^{3}$ a method of analysing qualitative data developed specifically for policy studies. The analysis therefore focused on the way people thought about multi tissue donation, the pattern of reasoning and the connections they made to other issues when agreeing to their family member's body being moved to the dedicated facility, and how they interpreted the information provided to them by NHSBT Tissue Services. Key themes were identified, coded and categorised. Atlas ti version 5.2, a qualitative software data package was used to store the collected data and support the coding process.

\section{Clinical Governance}

Approval to carry out this evaluation was given by the Senior Management Team of NHSBT Tissue Services.

\section{Findings}

\section{Response to recruitment initiatives}

All families that had agreed to the donation of their relatives' tissues being carried out at the DDF since it opened on $1^{\text {st }}$ October 2006, until two months before the planned start of the evaluation 31st April 2009, were considered for participation in the evaluation. During this time line there were 69 donation operations carried out at the DDF in Speke.

Of the 69 potential participants, 50 received recruitment letters [72\%]. Nineteen family members [27\%] were not sent recruitment letters for the reasons listed in Table 1. Recruitment letters were enclosed with a Participant Information Sheet explaining the aim of the evaluation and a reply slip by which potential participants could respond to the lead evaluator indicating their agreement to be contacted and their 
preferred mode and time of contact. A pre-addressed, stamped envelope for return of the reply slip was also included.

Ten responses to recruitment letters were received [20\%]. Of these 10 , nine requested an interview and one participant indicated that they did not want to talk about their relative's death, but were willing to answer questions sent to them by e-mail. Despite initial e-mail contact and an agreement to accept the interview questions there was no further response from this participant [ 3 attempts to contact].

Table 1. Potential study sample

\begin{tabular}{|l|c|}
\hline \multicolumn{1}{|c|}{ Potential sample } & $\mathbf{N}[\%]$ \\
\hline Potential participants & 69 \\
\hline No. of family members not contacted & $19[27 \%]$ \\
\hline Reasons for non-contact & $\mathbf{N}[\%]$ \\
\hline $\begin{array}{l}\text { Families requested no follow-up } \\
\text { communication after the donation. }\end{array}$ & $10[53 \%]$ \\
\hline Donor files unavailable & $4[21 \%]$ \\
\hline Consent not taken by Tissue Services & $2[11 \%]$ \\
\hline Family conflict & $1[5 \%]$ \\
\hline Eye only donor & $1[5 \%]$ \\
\hline No next of kin address available & $1[5 \%]$ \\
\hline Response Rate & $\mathbf{N}[\%]$ \\
\hline No of recruitment letters sent out & $50[72 \%]$ \\
\hline No of positive responses & $10[20 \%]$ \\
\hline
\end{tabular}

\section{Participants}

Of the 10 participants who responded, eight were women and two were men. Table 2 lists the relationship of the participants to the deceased and the mode of interview. Nine participants were contacted via e-mail or telephone, and a time and place for the interview to be carried out was agreed. Interviews were spread over a three month period [July - September 2009] due to one participant working out of the country four days out of five and one participant being out of the country for two months. 
Table 2. Mode of interview and relationship of participant to the deceased

\begin{tabular}{|c|c|c|c|}
\hline $\begin{array}{c}\text { Participant } \\
\text { No. }\end{array}$ & Gender & $\begin{array}{c}\text { Mode of } \\
\text { Interview }\end{array}$ & $\begin{array}{c}\text { Relationship to } \\
\text { deceased }\end{array}$ \\
\hline 01 & Male & Telephone & Wife \\
\hline 02 & Female & Telephone & Father \\
\hline 03 & Female & Telephone & Father \\
\hline 04 & Female & Face to face & Father \\
\hline 05 & Female & Telephone & Husband \\
\hline 06 & Male & Telephone & Brother \\
\hline 07 & Female & Face to Face & Father \\
\hline 08 & Female & Telephone & Father \\
\hline 09 & Female & Telephone & Husband \\
\hline
\end{tabular}

\section{Procedure for interviews}

Before commencement of the interview all participants were asked if they had any questions that they wished to ask. After any questions were answered to their satisfaction, all participants consented to the interview to take place. Consent was either signed in person at interview $[n=2]$ or recorded over the telephone $[n=7]$ with a subsequent hard copy being sent to the participant and returned to the lead evaluator.

All participants were asked the questions listed in the interview Schedule [Table 3] and all participants received a 'Thank you' letter from the evaluation lead. 
Table 3. Interview schedule Dedicated Donor Facility Evaluation

\begin{tabular}{|c|c|}
\hline Prea & \\
\hline $\begin{array}{l}\text { As I } \\
\text { tellin }\end{array}$ & $\begin{array}{l}\text { ve any details about your deceased relative, would you mind } \\
\text { tle about who we will be talking about? }\end{array}$ \\
\hline Ques & Jo. \\
\hline 1 & How was the issue of tissue donation raised with you? \\
\hline 2 & $\begin{array}{l}\text { What were your feelings when asked to donate your relatives' } \\
\text { tissues? }\end{array}$ \\
\hline 3 & Were you aware of tissue donation before you were contacted? \\
\hline 4 & $\begin{array}{l}\text { When you were asked for permission for your relative to be } \\
\text { moved to the dedicated donation facility in Speke, what was } \\
\text { your reaction? }\end{array}$ \\
\hline Promp & needed \\
\hline Did yo & ve concerns? \\
\hline What $\mathrm{g}$ & ons did you ask? \\
\hline Were $\mathrm{t}$ & questions answered to your satisfaction? \\
\hline How di & er family members react? \\
\hline 5 & $\begin{array}{l}\text { Could you tell me a little about the whole experience, how did } \\
\text { you feel about it? }\end{array}$ \\
\hline 6 & Do you feel the staff at the NRC were 'good at their job?' \\
\hline 7 & Is there anything that you feel was not done well? \\
\hline 8 & Is there anything that you feel was done well? \\
\hline 9 & $\begin{array}{l}\text { Could you tell me a little about your reasons for saying yes to } \\
\text { tissue donation? }\end{array}$ \\
\hline 10 & $\begin{array}{l}\text { Finally, if Tissue Services received a thank you from the } \\
\text { recipient family would you want to receive this communication? }\end{array}$ \\
\hline
\end{tabular}

No participants withdrew from the evaluation and follow up telephone calls indicated that whilst participants had been reminded of sad issues at the time of being asked to donate tissues, they were also positive regarding the opportunity to offer some feedback to Tissue Services.

\section{Findings from interviews}

\section{Preamble}

As is usual in qualitative analysis the findings and discussion will run in parallel. As the aim of this evaluation was to answer the questions that were set a priori, the findings from interview data are presented in the following section and are reported in direct response to the aims. Exemplar quotes are used to illustrate participants' views. 


\section{Aim 1: To understand the decision-making process of those family members who agreed to their deceased relative being moved to the DDF at Speke so that tissue retrieval could take place.}

As all participants had agreed to tissue donation [and although not a specific aim of the evaluation] the findings section will commence with a brief overview of contextualising information aimed at explicating some of the antecedents to agreement for tissue donation.

All but one participant was pro donation seeing it as a positive initiative in that it had the potential to help others ${ }^{b}$. The one negative stance was linked to wanting to leave the world 'with all they had come in to it with'. Two participants were on the NHS Organ Donor Register and one carried a donor card.

Four participants knew the wishes of the deceased regarding organ donation prior to death [three via family discussion and one via joint registration on the Organ Donor Register], and the rest did not know the wishes of the deceased. Their positive decision appeared to be based on 'the kind of person the deceased was' whereby they were perceived to be 'caring' people who having helped others during their lifetime would wish to do so after their death.

" I have got nothing to add only the fact that I am really happy that we did it [donate tissues] and I know that my [deceased] would have been happy as well because that's the sort of person that he was and I just feel that if you can help people in a small way without like blowing your own trumpet because that's what we are probably like as a family and my [deceased] was always a giver he would give rather than receive so and we are a bit like that also I think that it is a good thing" [2:16 (114:114)].

${ }^{\mathrm{b}}$ One participant family had been involved in publicity initiatives organised by Tissue Services. 
In one case the participant was unaware that her deceased relative had signed a donor card until she was told this by a tissue coordinator. This information led directly to the donation as the participant was unwilling [at the time of interview] to consider donation for herself.

" that was the first time I knew that he was a donor and then of course in the process of the shock of [deceased] having died is trying to focus on what I was being told on the phone, also working with your own thought processes of [what a] donor card meant to me, organs, didn't mean at the time blood tissue eyes bone whatever, but she was very very good she dealt with me very empathetically, she was very friendly, she was very respectful, very sincere and very grateful that I had sort of said yes and I said I am saying yes because my [deceased] had a donor card; you need to be aware that perhaps I would think differently if you were asking me to make a decision if he hadn't got a donor card" [7:4 (7:7) - 7:6 (7:7)].

An important issue from the analysis regarding decision making was the fact that a positive decision was made in the light of very little or no knowledge of tissue donation by all but one of the participants ${ }^{c}$. Apart from one well informed individual, participants were very much less aware of tissue donation than organ donation, and were often surprised about what could be donated ${ }^{\mathrm{d}}$.

"the first I had any knowledge of tissue donation was a phone call from Liverpool ... I was actually amazed how many different pieces that they could take how many slivers that they could actually utilise" [6:2(40:40)-6:14 $(169: 169)]$.

In seeking to illuminate these positive donation responses in the light of little knowledge and the majority of participants not knowing the wishes of the deceased, analysis focussed on exploring the role of preemptive information given to family members by hospital staff, and contact by the tissue coordination staff within the National Recruitment

\footnotetext{
' One participants' cousin had received two kidney transplants in the past and this individual was very well informed about tissue donation.

${ }^{\mathrm{d}}$ One participant had received a transplant and whilst being well informed about solid organ donation was poorly informed about tissue donation.
} 
Centre $[N R C]$ in the DDF.

\section{Pre-emptive information}

Two participants were in receipt of a leaflet about tissue donation that had been handed to them by Accident and Emergency [A\&E] staff. Two participants raised the issue of donation with health professionals when their family member was admitted to A\&E. One participant had noticed a poster within the A\&E department and after a family discussion had then contacted Tissue Services. Four participants received a 'cool call' from tissue coordination staff within the NRC.

"and it was actually the nursing sister in casualty who gave us a leaflet and all she said was, obviously we had had a cup of tea etc and we had seen [the deceased] and that, and then she said about this she gave us this leaflet for tissue donation and would we accept it and at the time I just said oh yes and I just sort of had all the paperwork together and got back to [the deceased] and then it was the next day in this house that I got a call off somebody to say that we had been given this leaflet and would we be interested and so then what I did after that because obviously I had forgotten all about being given the leaflet to be truthful at that point, but what I did was I asked them to explain what it entailed, which they did, and then I said I would discuss it with my mum, so they arranged to ring me back" [2:2(41:41)]

Clearly, whilst both participants did not read the leaflet provided at the time it was given to them, the fact that the term 'tissue donation' had been raised was registered by them, and whilst the topic of tissue donation was not discussed by A\&E staff, neither of these participants were 'shocked' by a call coming from tissue services. This was not the case with those who received a 'cool call'.

"I found the experience traumatic. It came as a bit of a shock luckily I had my family around me so when I finished the conversation on the phone we had a chat together, but having said all that I couldn't think of any other way that they could approach it. I can't think how it could have been bettered, but it was traumatic definitely. The reason is that I was fourteen and a half when he was born and so he was like my own child as it were he was like six when we got 
married so it is not like a sibling type thing, but of course they weren't to know. I did find it quite traumatic but how they did it and what they did was not, it was not a problem, it wasn't a problem it was just the whole process I did find difficult" [6:3 (53:53)].

\section{The request process}

All participants found a cool call difficult, usually describing it in terms such as 'traumatic' 'difficult', 'shocking' but as noted above, whilst the topic of the call was distressing or difficult, as was some of the content, the manner in which the calls were carried out was overwhelmingly positive.

"It was excellent because I do remember, it was a lady, I don't remember her name, but she was really lovely and she was very patient. Obviously it was something that I had never ever thought was going to happen, I never realised that I would be doing something like that because I didn't know anything about it, but because she was very experienced in the job that she does and she was very knowledgeable about the way she put the questions across, when she had to do the very long questionnaire regarding things like have you ever been in contact with Aids etc she was putting me at ease. She pre-warned me this question might upset me slightly and said that it is not intended to offend. Questions like, stuff that I would never imagine my [deceased] to be around but they have got to ask that because obviously they couldn't go ahead and do the tissue donation if that was the case. So what I am saying is the way she put the questions across the way she explained everything it was fine I could understand exactly what she was on about she was very good on the phone" [2:11 (74:74)].

There is very little empirical work exploring the interaction between tissue coordinators and family members who are approached and requested to consider tissue donation and of this almost all focuses on corneal donation ${ }^{6-10}$. One of only two studies investigating the interaction between family members and tissue coordinators was carried out in Australia by Beard et al [2002] ${ }^{11}$. Like this evaluation Beard and colleagues [2002] aimed to explore family members experiences and to 'use this information to improve the existing 
service' [p:43]. Beard et al (2002) sent out questionnaires to 339 family members of deceased tissue donors gaining 197 responses [58\%]. The majority of participants had been approached about tissue donation via the telephone [44.9\%][sic] and the majority of participants held a positive view of donation prior to the request for tissue donation [35.2\%][sic].

In asking family members to comment on what could be improved, Beard et al [2002] listed the following four areas, i) the need to know the outcome of donation ${ }^{\mathrm{e}}$, ii) the need for education about tissue donation to minimise shock, iii) how too much detailed information was given, and iv) rephrasing 'harsh' questions, such as, 'whether my father had sex with another man' [p: 46]. This latter point is one that has not been addressed in research and yet the discomfort that family members express is a frequent anecdotal comment by tissue coordinators.

\section{Life style and behavioural risk questions}

Whilst there are legal, policy, safety and quality requirements underpinning the questions asked of family members re the deceased lifestyle and behaviours, it may be necessary to review the impact that such questions may have on consent rates due to: i) the shocking nature of the questions; ii) the inability of the individual asked to answer these questions; iii) the 'social acceptability' of such questions being asked post death. Experts may argue that these questions are asked of blood donors on a daily basis [without causing distress], but this view ignores the role that death and bereavement play in the emotional response of family members. A blood donor can answer said questions for themselves, a deceased donor cannot; therefore placing the next of kin in the position of talking about sensitive issues without: i) a prior discussion with the deceased; and ii) at a time when they

\footnotetext{
e Also an issue in solid organ donation, see Sque et al, [2005] ${ }^{15}$
} 
are emotionally and cognitively ill equipped to answer them. As this evaluation has indicated that family members know little about tissue donation; we therefore propose that it is unlikely that they know anything about the nature of the questions that are asked during the request for multi tissue donation. This lack of knowledge increases the potential for this questioning to have a negative impact on both consent rates and bereavement.

\section{Aim 2: To identify any concerns that family members had about their relative being moved and their views on how these concerns were addressed.}

The decision making process underpinning agreement by family members for their deceased relative's body to be moved to the DDF for tissue donation appeared to be linked to: i) a positive rapport with the person making the request; ii) satisfaction with the information provided to the family about what would happen; and iii) trust in that what was being said would happen. The main concern was whether their deceased relative would be successfully moved and returned.

"I suppose you know in hindsight then it is a reasonable request you know, just I suppose you worry about things like that don't you when you are in shock, like oh God is everything going to be alright he is going to be moved you know, it was just a unfamiliar thing isn't it, but no I think it was alright" [3:5 (49:49)].

Participants indicated that they felt that the tissue coordinators were aware of the anxieties that family members may have as they dealt with all the post death administration and funeral arrangements.

"They talked me through what would happen and they dealt with all that [questions and concerns] I am sure. They did let me know when his body could be released so we could sort out get my [deceased] death certificate etc but they kept us informed as things were happening they did it all they arranged everything" [7:9 (61:61)]. 
An influential factor in these positive responses to deceased donors being moved to the DDF was the service provided by funeral directors. Two participants indicated that the funeral directors were 'very knowledgeable' about tissue donation often supporting and expanding on what the tissue coordinator had said. This 'reinforcement' of information appeared to be of help to family members and supports the evidence that indicates that a greater awareness of both tissue donation, and the processes that are required to facilitate it need to be in the public domain so that the 'shock' that family members in this evaluation experienced when receiving a cool call may be modified.

\section{Aim 3: To gain insight into the perceptions of family members regarding the 'service' provided to them by NHSBT Tissue Services.}

Participants felt well informed about all aspects of the donation procedure, but there were two instances where participants were distressed by what they saw when they viewed the body post donation. In the situation articulated in this first quote the participant is 'upset' that what she had been told [and had passed on to other family members] was not what happened.

"and then he said they would take the bones of the legs, well he said they would take them from the thighs to the knees. He said that it wouldn't be noticed because they would pad them out and what have you. Well, I was quite upset over that, could have been down to the funeral director, could have been down to the hospital, I just don't know you know, and that was the only thing that really sort of cracked me over the whole issue you know because he looked that he had none, he was flat you see and I looked and he had no shape there at al. We did say we were going to go ahead with the donations, that was fine and he did say that he wouldn't look any way disfigured or anything because they would pad them out and things like that, but when I saw his body I was quite disappointed, it is not fair for the kids because they said 'oh my [deceased] got no legs' I said he has I said they have only took the bones. It was a bit upsetting the rest of him looked fine, yes as I expected, they warned me about the bruising under his eyes because they 
were taking his eyes, there was no bruising or anything. He has come back lovely bar for his legs; it was the only thing that I was disappointed in actually" [5:5 (69:69)5:6(73:73) 5:7 $(81: 81) 5: 8(85: 85)]$.

This situation puts the tissue coordinator in an invidious position as he/she is not in control of how the body looks post donation ${ }^{f}$. It is essential that if the present methods of reconstruction are falling short of family member's expectation then a review of current practice is undertaken. As audits of family members' experiences and views post donation are not routinely carried out this could be an issue that leads to negative 'local' publicity about tissue donation. This is to be avoided as bereaved family members may become community educators in relation to organ and tissue donation ${ }^{20}$, as is the case for one participant in this evaluation. The 'evidence' going into the community needs to underline the 'message' going to the family that the deceased is accorded dignity and respect during and after tissue donation. Despite the above case the overwhelming message from families was that the service they received from the NRC was $\mathrm{good}^{\mathrm{g}}$.

\section{Summary}

Findings from this evaluation have clearly indicated that family members know very little about multi tissue donation before they were approached to consider it. This lack of knowledge contributes to the reaction that tissue coordinators face when they request that family members consider and consent to tissue donation. Reactions were more extreme in those family members who received a cool call. Preemptive information/discussions, a pro donation stance, and knowing

\footnotetext{
${ }^{f}$ Queries from retrieval teams are discussed within the CGM and issues such as this can be raised there, but only if TS know of such problems. As neither of these families had contacted TS with their concerns this underlines the importance of regularly auditing families so that issues such as these do not go unaddressed.

${ }^{\mathrm{g}}$ The issue of this reconstruction was investigated by the manager of the NRC. The retrieval team indicated that both bodies had fully reconstructed legs [that did not look flat] when they left the DDF. There was then discussion about the possibility of the prothstesis moving during the transfer back to the hospital mortuary, and thence onto the funeral directors. If this is the case then the utility of present modes of reconstruction may need to reviewed.
} 
the wishes of the deceased prior to request appeared to moderate reactions and would suggest that initiatives linked to these findings may, potentially, increase consent rates.

The process of reasoning behind both agreeing to tissue donation and movement of the deceased to the DDF by family members was fundamentally, 'the benefit to others' that tissue donation would bring, and fulfilling the wishes of the deceased [when known]. An enabling factor within this process was the positive rapport that was developed between the tissue coordinator and family member during the approach and request for multi tissue donation ${ }^{\mathrm{h}}$. Family members 'trusted' that their deceased relative would be treated with respect and dignity, and that they [family member] would be kept fully informed about the location of their family member. This trust was damaged when post tissue donation reconstruction procedures fell short of family members' expectations which were based on information provided by tissue coordinators.

A important finding was the fact that elements of the approach and request were 'blurry' or poorly remembered by family members. Whilst this is not surprising in light of the recent bereavement and the focus of their thoughts being on their loss and the demands of the usual post death rites and rituals, it is of concern in relation to family members recollection of what was consented to. Bearing in mind the 'shock' experienced by those family members who received a cool call as opposed to a traditional approach, future work should explore whether there is greater recollection of the approach for tissue donation in those families who receive a traditional approach compared to those who received a cool call.

\footnotetext{
${ }^{h}$ Reported in work with solid organ donation, see Sque et al [2005] ${ }^{15}$
} 


\section{Critique of the evaluation}

Bearing in mind the low response rate for this evaluation, and the fact that no family who declined donation was approached to participate, we have only one lens to view the service provided. Having said this it should be acknowledged that family members were positive about the interactions with tissue coordinators. The caveat that must frame the findings of this evaluation is the low response rate and the fact that all but one participant held a pro-donation stance. Whilst this may not be important in relation to decision making about whether to expand the geographic area from which deceased donors can be moved to the DDF [as family members can refuse] it is a constraint in relation to comments regarding participants' satisfaction with the service provided.

\section{Future work}

Based on this evaluation, a two year programme of auditing family members' experiences of tissue donation, seeking feedback to underpin practice development, would be of great value in addressing some of the issue raised in the findings.

A survey aiming to recruit from the population of family members approached about tissue donation [those who say yes, and those who say no] via the NRC should be carried out with the aim of using this information to guide practice review and development, for example: the nature of the questions posed to family members and the core characteristics required in the information shared. As tissue donation is a time limited, once only, opportunity it is essential that families are supported in making decisions that are right for them. 


\section{Acknowledgements}

We would like to acknowledge and thank the participants for their central contribution to this evaluation; individuals who so generously gave up their time to meet with, or talk to, the lead evaluator over the duration of the project. Your willingness to share your experiences is greatly appreciated.

We would like to personally thank: Jackie Dawber who orchestrated all aspects of initial and continuing administrative contact with family members, and Emma Winstanley, who initiated this evaluation and reviewed early drafts. 


\section{References}

1. Directive [2004]/23/EC of the European Parliament and of the Council on Setting Standards of Quality and Safety for the Donation, Procurement, Testing, Processing, Preservation, Storage and Distribution of Human Tissues and Cells, available at: http://eurlex.europa.eu/LexUriServ/LexUriServ.do?uri=OJ:L:2004:102:0048:0058:en:P DF [accessed 05.11.08]

2. Sque M, Long T, Payne S, Roche W, Speck P. [2008] The UK postmortem organ retention crisis: a qualitative study of its impact on parents. Journal of the Royal Society of Medicine, 101: 71-77.

3. Ritchie J and Spencer L [1994] Qualitative data analysis for applied policy research. In: Bryman A, Burgess R, eds. Analysing qualitative data. London: Routledge,173-194.

4. Pope C, Ziebland S, Mays N. [2000] Qualitative research in health care: analysing qualitative data. British Medical Journal, 320: 114-116.

5. Sque M. (1996) The experiences of donor relatives, and nurses' attitudes, knowledge and behaviour regarding cadaveric donotransplantation. PhD Thesis, University of Southampton, Southampton, UK.

6. Williams KA, White $M$, Badenoch $P$, Wedding $T$, Alfrich S, Sawyer MA, Noack LM, Johnstone E, Zilm G, Coster DJ. [1990] Donor cornea procurement: six-year review of the role of the eye bank in South Australia. Australian New Zealand Journal of Ophthalmology,18(1):77-89.

7. Doering J]. [1996] Families' experiences in consenting to eye donation of a recently deceased relative. Heart and Lung, 25:72-78.

8. Muraine M, Menguy E, Martin J, Sabatier P, Watt L, Brasseur G. [2000] The interview with the donor's family before postmortem cornea procurement. Cornea, 19 (1):12-16.

9. Gain P, Thuret G, Pugniet JL, Rizzi P, Acquart S, Le Petit JC, Maugery J. [2002] Obtaining cornea donation consent by telephone. Transplantation, 73 (6): 926-929.

10. Geissler A, Paoli K, Maitrejean C, Durand-Gasselin J. [2004] Rates of potential and actual cornea donation in a general hospital: impact of exhaustive death screening and surrogate phone consent. Transplantation Proceedings, 36:2894-2895.

11. Beard J, Ireland L, Davis N, Barr J. [2002] Tissue donation: What does it mean to families? Progress in Transplantation, 12 (1): 42-48.

12. Beaulieu D. [1999] Organ donation: the families' right to make an informed choice. Journal of Neuroscience Nursing, 31 (1): 37 -42. 
13. Pelletier M. (1993) The needs of family members of organ and tissue donors, Heart and Lung, 22(2) pp. 151-157.

14. Siminoff L A, Gordon N, Hewlett J, Arnold RM. [2001] Factors influencing families' consent for donation of solid organs for transplantation. JAMA, 286 (1): 71-77.

15. Sque M, Long T, Payne S.(2005) Organ donation: key factors influencing families' decision-making. Transplantation Proceedings 37 (2) pp. 543-546.

16. Long T. [2007] Supporting Family members decision-making regarding organ donation, In Sque M and Payne S [Eds] Organ and tissue donation: An evidence base for practice, Open University Press, Maidenhead.

17. Verble M, and Worth J. [1999] Dealing with the fear of mutilation in the donation discussion. Journal of Transplant Coordination, 9: 54-56.

18. Long T, Sque M, and Payne S. [2006] Information sharing in hospitals: its impact on donor and nondonor families' experiences in hospital. Progress in Transplantation, 16: (2): 144-149.

19. Kent, B. [2007] Tissue donation and the attitudes of health care professionals, In Sque M and Payne S (Eds) Organ and tissue donation: An evidence base for practice, Open University Press, Maidenhead.

20. Salih MA, Harvey I, Frankel SDJ, Coupe DJ, Webb M, Cripps, HA. [1991] Potential availability of cadaver organs for transplantation. British Medical Journal, 302 (4 May):1053-1055. 